\title{
Clinical management of squamous cell carcinoma in an 8-year-old White Arewa Stallion: A case Report
}

\author{
Ochube G.E. \\ Department of veterinary surgery and radiology, Ahmadu bello university, Zaria, \\ Correspondence: gabrielochube2000@gmail.com; +2348035969048
}

\begin{abstract}
An 8- year- old white Arewa stallion was hospitalized in our facility (Veterinary Teaching Hospital, Ahmadu Bello University, Zaria) with the primary complaints of fleshy growth on the lower eyelid of the right eye and unilateral left scrotal enlargement. Biopsies were taken via fine needle aspirate from the growth and sent to histo-pathology laboratory of the Department of Veterinary Pathology, Ahmadu Bello University Zaria. Histo-pathology results confirmed $3^{\text {rd }}$ stage of squamous cell carcinoma (SCC). Treatment was instituted using vincristine sulphate at a dose rate of $0.025 \mathrm{mg} / \mathrm{kg}$ and a cyclo-oxygenate 2 inhibitor, diclofenac sodium at a dose rate of $0.5 \mathrm{mg} / \mathrm{kg}$ for 6 cycles. The surgery was shelved because of the outcome of the therapy. The tumour regressed and the scrotum returned to normal size. The patient recovered and was discharged 2 weeks after the 6 weeks therapy. The clinical relevance of note is that the above cocktail might be employed in managing early stage of SCC therapy where surgery is not required.
\end{abstract}

Keywords: Albino horse, carcinoma, vincristine sulphate treatment

\section{INTRODUCTION}

Squamous-cell carcinoma (SCC) is the most common cancer of the eye, peri-orbital area and penis. It is the second most common cancer in horses, accounting for 12 to $20 \%$ of all cancers diagnosed (Torrontegui et al., 2009). While SCC has been reported in horses aged 1 to 29 year, most cases occur in 8- to -15 year-old horses, making it the most common neoplasm reported in older mares (Knottenbelt et al., 2000). Carcinomas are tumours derived from epithelial cells and SCC results from transformation and proliferation squames, epidermal skin cells that become keratinized (Knottenbelt et al., 2003). Squamous-cell carcinomas are often solitary, slow-growing tumors that cause extensive local tissue destruction. They can metastasize to other organs, with reported rates as high as $18.6 \%$, primarily to the lymphnodes and lungs.

Tumours related to SCC can appear anywhere on the body, but they are most often located in non-pigmented skin near mucocutaneous junction (where skin meets membranes) such as eyelids, around the nostrils, lips, vulva, prepuse, penis or anus. The tumours are raised, fleshy, often ulcerated or infected and may have an irregular surface. Rarely, primary SCC develops in the oesophagus, stomach (non-glandular portion), nasal passages and sinuses, the hard palate, gums, guttural pouches and lungs. The eyelid is the most common site accounting for $40-50 \%$ of cases, followed by the genitalia in males ( $25 \%$ of cases) and females (10\% of cases) (Top et al., 2008).

Horses with lightly pigmented skin, such as those with a gray hair coat or white faces are especially prone to developing SCC, and some breeds, such as Clydesdales may have genetic predisposition. Exposure of light coloured skin to UV light is often a predisposing factor, but lesions may occur in dark skin and in areas that are not usually exposed to sunlight such as around the anus. Build-up of smegma ("the bean" in horseman's term) on the penis is also linked to SCC and is thought to be a carcinogen through penile irritation. Pony, geldings and work horses are more prone to developing SCC on the penis, due to less frequent penile washing when compared to stallions. Equine papillomavirus- 
2 has also been found within penile SCC's, but has not been determined to cause SCC (Valentine, 2006).

Before treatment of SCC is initiated, evidence of metastasis must be determined either by palpation and aspiration of lymph-nodes around the mass or in smaller horses, by radiographs of the thorax (Giuliano, 2005). Small tumours found early in the disease process (most frequently on the eyelid) can be treated with Cisplatin or radiation with favourable results (Aliu, 2007). For some advanced cases, surgical removal of the eye (enucleation), or mass debulking can be curative provided all cancerous cells removed (wide margin obtained) and there is no metastasis (Cancer Cell International, 2014). However, young horses usually geldings less than 8-year-old that have a hard or "wooden" texture SCC on the glans penis have a very poor prognosis for treatment and recovery. Regular washing of the penis and prepuse in males as well as cleaning the clitoris fossa (the groove around the clitoris) in mares is recommended to remove smegma build-up, which also gives the practitioner room for inspection for suspicious growth of pathogens on the penis or the vulva (Zhang et al.,2013).

\section{CASE REPORT}

An 8-year-old white Arewa stallion weighing $400 \mathrm{~kg}$ with a height of $125 \mathrm{~cm}$ was presented to Ahmadu Bello University Veterinary Teaching Hospital, Zaria, Nigeria with the primary complaints of growth on the right eye and unilateral left scrotal enlargement. Physical examination revealed normal values for all vital parameters (Table I), there were purulent discharges from the affected eye. Body score of the patient was rated good. History revealed that the patient was the only animal in its "room" like stable with a window directly facing the sun rays. Patient's feed comprised millet, grass and maize. Patient had no previous vaccination or medical record.

Table 1. Patient's vital parameters on presentation

\begin{tabular}{r|c|c|}
\hline Parameters & Patient values & Reference \\
\hline Temperature & 39 & $37.2-38.3^{\circ} \mathrm{C}$ \\
Pulse rate & 28 & $28.0-44.0 \mathrm{~b} / \mathrm{m}$ \\
(beats/min) & & \\
Respiratory & 20 & $10.0-24.0 \mathrm{c} / \mathrm{m}$ \\
rates & & \\
(cycles/min) & &
\end{tabular}

*Source: Radostits 2009

\section{LABORATORY INVESTIGATION AND RESULTS}

Blood samples were taken and submitted to Parasitology and Clinical Pathology laboratories for parasitic screening and base-line haemogram (Table II), respectively. Weekly blood sample was also analyzed in the Clinical Pathology laboratory to ascertain the effect of chemotherapy on the haemogram for the period of six cycles that the chemotherapy was administered. Biopsy of the growth on the third eyelid was taken using a fine needle aspirate. Parasitology laboratory results revealed no parasite found, while results for histopathology were positive for stage III SCC.

\begin{tabular}{|c|c|c|}
\hline Parameters & $\begin{array}{l}\text { Patient's } \\
\text { value }\end{array}$ & $\begin{array}{l}\text { *Reference } \\
\text { values }\end{array}$ \\
\hline $\mathrm{Hb}(\mathrm{g} / \mathrm{dL})$ & 10.3 & $10.1-16.1$ \\
\hline $\operatorname{PCV}(\%)$ & 28 & $24-50$ \\
\hline Total leucocytes $\left(\times 10^{9} / \mathrm{L}\right)$ & 18.1 & $4-12$ \\
\hline Neutrophils (x1097/L) & $15.6(20)$ & $(0.4-6)^{*} 10-50$ \\
\hline Lymphocytes (x109/L) & $1.16-$ & $(1.6-9) * 40-75$ \\
\hline Monocytes (x109/L) & $5.1 *(65)$ & $(0.079) * 0-6$ \\
\hline Eosinophils (x109/L) & $0.44 *(5)$ & $(01.2)^{*} 0-0.78$ \\
\hline Basophils (x109/L) & $0.81 *(10)$ & $(0-086) * 0-3$ \\
\hline \multirow[t]{2}{*}{ Bands $\left(\times 10^{9} / \mathrm{L}\right)$} & $1.4 *(0)$ & $0.0-0.1$ \\
\hline & $0 *(0)$ & \\
\hline
\end{tabular}

$\mathrm{NB}: \mathrm{Hb}=$ Haemoglobin, $\mathrm{PCV}=$ Packed Cell Volume Values in parenthesis represent relative values Values with (*) represent absolute values *source $=($ Duncan and Prasse's)

\section{CASE MANAGEMENT}

Vincristine sulphate was administered at $0.025 \mathrm{mg} / \mathrm{kg}$ (total dose of $10 \mathrm{mg}$ ) I.V for 6 cycles (dosage was calculated using the body surface area) alongside diclofenac sodium at 5 $\mathrm{mg} / \mathrm{kg}$ (total dose of $2000 \mathrm{mg}$ ) i/m o.d $\times 7 / 7$. Terracotryl ${ }^{\circledR}$ eye ointment (tetracycline and hydrocortisone) was employed as eye drop daily for 2 weeks. Tetanus toxoid was given for prophylaxis against tetanus. The chemotherapy outcome was positive and the planned surgery consequently shelved. The tumour regressed and melted completely and the scrotum returned to normal size.

\section{DISCUSSION}

Management of stage III SCC entails instituting chemotherapy for 3 to 6 cycles followed by surgical debulking of the tumour if necessary (Knottenbelt et al., 2009). For this case report, vincristine sulphate, which is a vinca alkaloid, was used. The drug is a sulphate salt of a natural alkaloid isolated from the plant Cattaranthus roseas (vinca rosea) with anti-mitotic and anti-neoplastic activities. Vincristine binds irreversibly to microtubules and spindle 


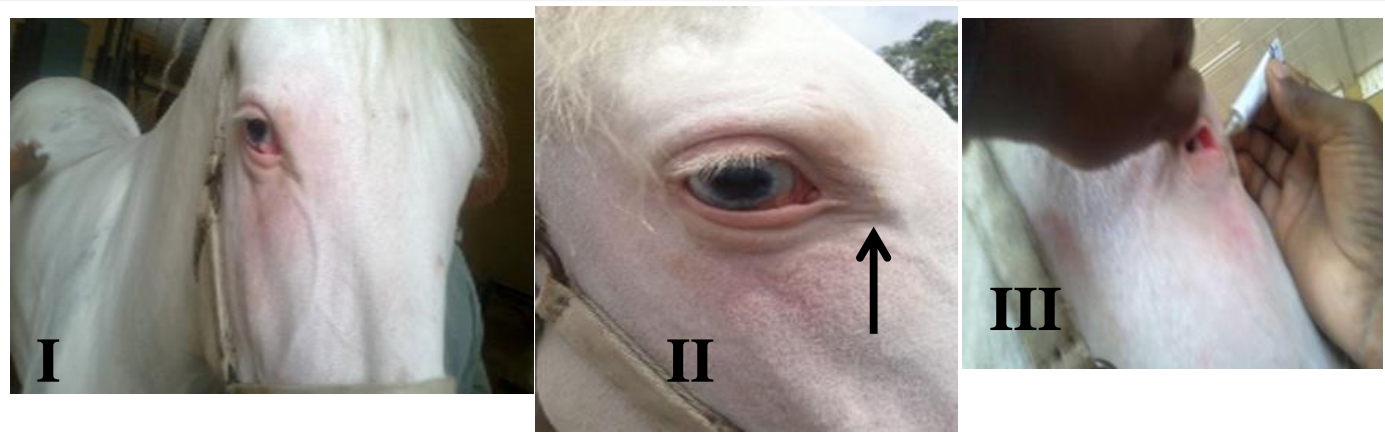

Figure I: Showing fleshy protuberance of the tumor before (I) and after (II) Terracotryl eye suspension application (demonstrated in III)

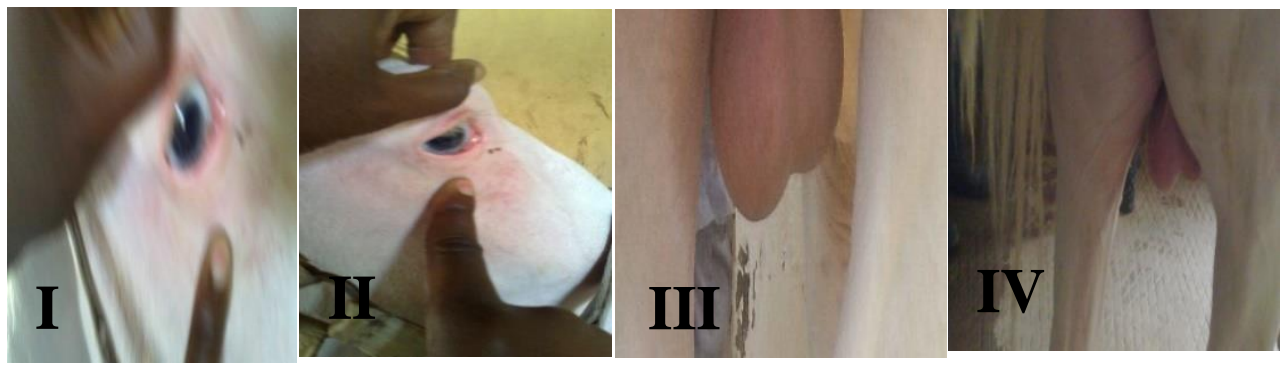

Figure II: Images showing the outcomes of 8 weeks therapy with complete disappearance of tumour (I and II) and unilateral scrotal swelling before (III) and after (IV) the therapy

protein in S-phase of the cell cycle and interferes with the formation of the spindle (Aliyu, 2007).

Vincristine sulphate is used either alone or in conjunction with other oncolytic drugs for the treatment of Leukemia, including acute lymphocytic leukemia, chronic lymphocytic leukemia, acute myelogenous leukemia and blastic crises of chronic myelogenous leukemia (Beuchner et al., 2009).

In this case study, vincristine sulphate was used as a cocktail with diclofenac sodium. The drug is a synthetic antiinflammatory, anti-pyretic and analgesic drug, whose mode of action is inhibition of postaglandin synthesis by inhibiting the transiently expressed postraglandrin-endo-peroxide synthase-2, also known as cyclooxygenase -2 (COX-2) (Giuliano, 2009 ; Knight et al., 2011).

The enzymes responsible for producing postaglandin are called cyclooxygenase (COX). There are two types of COX enzymes, COX-1 and COX-2. Both enzymes produce postaglandin that promote inflammation, pain and fever (Cancer Cell International, 2014). However, only COX-1 produces prostraglandrins that activate platelets and protect stomach lining (Foley et al., 1991; Zhang et al., 2013). By the synergistic action of both drugs as described above, the tumour melted and regressed completely after 6 cycles of administering vincristine sulphate and diclophenac cocktail. The initial pancytopenia (week 1 haemogram) seen on the haemogram reversed to leukocytosis (tending to a left shift) possibly due to therapy that boosted the immunity. The unilateral scrotal swelling also regressed to normal. To the best of our knowledge, this is the first time in Zaria and its environing that a combination of both drugs was used to manage SCC in horses successfully without surgery. Followup was consistent for the past six month and no evidence of tumour re-growth was observed.

\section{CONCLUSION}

This case report can be concluded by saying that, although SCC is routinely managed by chemotherapy and surgical debulking of the tumor depending on the stage, a cocktail of vincristine sulphate and diclofenac sodium was found to be efficacious in the management of the condition and might be helpful in managing early stage of SCC. We advised the client to prevent further exposure of the patient to direct sunrays as this might trigger the condition.

\section{REFERENCES}

Aliu, Y.O. (2007) Veterinary Pharmacology, $1^{\text {st }}(\mathrm{Ed})$. Tamze publishing company, Zaria, Nigeria. Pp. 449-441.

Beucher, M.V. (2009) Skin tumours". In Norman Edward Robinson and Kim A. Spray-berry. Current therapy in equine medicine $\left(6^{\text {th }}\right.$.ed). St. Louis Elsevec Health Sciences, Pp. $692-697$.

Cancer Cell International (2014). Journal of Clinical Oncology Pp., 22-24

Foley, G.L., Valentine B.A., Kincaid A.L. (1991)“Congenital and Acquired Melanocytomas 
(Benign Melanomas) in eighteen young Horses" Veterinary Pathology, 28(5): 363 - 369.

Giuliano, Elizabeth A. (2005). "Ocular Squamous Cell Carcinoma". In Norman Edward Robinson and Kim A. Spray-berry. Current therapy in equine medicine $\left(6^{\text {th }}\right.$. ed $)$. St. Louis Elsevec Health Sciences. Health Sciences. Pp. 639.

Knight, C.G., Monday J.S., Peters J., Dvnovska M. (2011) "Equine penile squamous cell carcinomas are associated with the presence of equine papillomatosis Type 2 DNA sequences", Veterinary Pathology.

Knottenbelt J., Derek C., Donald F., Kelly C. (2000)“The diagnosis and treatment of peri orbital sarcoid in the horse: 445 cases from 1974 to 1999", (PDF) Veterinary Ophthalmology. 3:169-191

Knottenbelt J, Derek C (2003) "Basic Principles of diagnosis and management of neoplasia in horses" (PDF) proceedings of the annual meeting of the Italian Association of equine Veterinarians, Pisa, Italy, XIV congress.

Knottenbelt J, Derek C; John W. McGarry (2000) "Neoplastic Conditions" Paswells principle and practice of equine dermatology, London: WB Sanders. PP.377 - 439 .
Lin li., Xin-guang Riu., Peng-wei IV., Pang Wang. (2014) Cancer Cell International, Vol.14 Issue 1, pre ceiling, Pp1-11

Radostits, Otto M., Clive C. Gay., Douglas C. Blood \& Kenneth W. Hinchcliff. (2009). A textbook of the diseases of cattle, sheep, pigs, goats, and horses $9^{\text {th }}$ edition Pp. 2983. W.B Saunders

Top J.G.B., Heer N., Klein W.R., Ensink, J.M., (2008)'Penile and prenuptial tumors in the horse. A retrospective of 114 affected horses`. Equine Veterinary journal. , 40(6):528-532.

Torrontegui, B.O., Reid S.W.O, (1994) "Clinical and pathological epidemiology of the equine sarcoid in a referral population" Equine Veterinary Education. , 1994, Pp 6:85-88.

Valentine, Beth A. "Neoplastic".(2006) In Joseph Bertone. Equine geriatric medicine and Surgery. St. Louis. Elsevec Health Sciences. , Pp 147 - 167.

Zhang X.H., Giuliano M., Trivedi M.V., Schiff .R, Osborne C.K.(2013) Metastasis dormancy in estrogen receptor-positive breast cancer. Clinical Cancer Research, 19(28):6389-6397.

Article history:

Received: Nov. 11, 2021,

Revised: Dec. 18, 2021

Accepted: Dec. 30, 2021 